\title{
EL LÈXIC MARINER DE LES POESIES D’AUSIÀS MARCH I LA SEUA DIMENSIÓ POÈTICA*
}

\author{
RAFAEL ALEMANY I FRANCESC XAVIER LLORCA IBI
}

\begin{abstract}
The constitutive lexicon of Ausiàs March's poems is characterized for belonging, semantically, to very diverse fields. Among these fields, the one related to the sea is especially worthy to be analyzed. In this article, we propose, by statistical basis, to value the extension and the limits of the poetical dimension of the sea-related lexicon found in the marquian songbook. To accomplish this objective, we offer: an inventory of every word connected to this semantic field, complemented by its lexicographical definitions, graphical and inflectional variants plus number of occurrences of each one and every textual reference which corresponds to; a classification of the lexical repertoire obtained in semantic subfields, which has been arranged depending on its specific quantitative weight; a relation of every poem in which the sea-related lexicon is centered, according to its diminishing order of ocurrences, and, finally, a conclusive valuation of the poetical scope achieved thanks to this lexicon across Ausiàs's work.
\end{abstract}

\section{INTRODUCCIÓ}

$\mathrm{E}_{1}$ lèxic constitutiu del poemari d'Ausiàs March comprèn un total de 3.317 lemes, que es manifesten en 7.876 variants gràfiques i de flexió documentades en 77.349 ocurrències. ${ }^{1}$ Aquest lèxic es caracteritza per pertànyer a un elevat nombre de camps semàntics, que palesen una diversitat $i$ una riquesa conceptual considerables: l'amor, la mort, les contradiccions del jo líric, la natura, la religió, la teologia i la mística, la ciència i la medicina, l'univers domèstic i quotidià, etc. (Hauf I 28-I37). Entre aquests camps, ocupa un lloc rellevant el relacionat amb el món mariner, que tan bé coneixia l'autor no sols per haver transcorregut la seua existència en indrets costaners, sinó també per la seua participació jovenívola en la primera campanya marítima militar del rei Alfons el Magnànim per la Mediterrània; tot això sense oblidar que, en l'aprofitament poètic de certs referents mariners per part de March, també influeixen alguns models estrictament literaris antics i medievals (Leveroni; Zimmermann, La Mediterrània).

\footnotetext{
"Aquest treball s'ha realitzat dins del marc del projecte de recerca FFI2008-00826, finançat pel Ministeri de Ciència i Innovació del Govern d'Espanya, que es desenvolupa al si de l'Institut Interuniversitari de Filologia Valenciana (Universitat d'Alacant).

${ }^{1}$ Ens basem en Alemany, $i$ en les concordances lematitzades pròpies i inèdites a partir de les quals s'elaborà aquesta obra. Vegeu també Flam, Hauf, Lara i Santanach/Torruella.
} 
Malgrat que la relació de la poesia d'Ausiàs March amb l'univers mariner ja ha estat objecte de l'atenció d'alguns estudiosos des de diverses perspectives, ${ }^{2}$ gosem tornar-nos-hi a endinsar des d'un angle que, per bé que inevitablement puga incidir en aspectes ja tractats, incorpora la novetat d'establir unes bases estadístiques eficaces que permeten obtenir unes conclusions més precises sobre l'extensió i els límits de la dimensió poètica del lèxic mariner del cançoner marquià. Així, doncs, partim d'un inventari dels lemes que hi trobem relacionables amb aquest camp semàntic, dels quals oferim: $a$ ) les definicions lexicogràfiques que els corresponen en els contextos en què apareixen; $b$ ) les variants gràfiques i de flexió concretes en què es documenten, i c) el nombre d'ocurrències de cadascuna de les variants ${ }^{3} \mathrm{i}$ les referències textuals respectives. ${ }^{4}$ En segon lloc, classifiquem el repertori lèxic obtingut en subcamps semàntics, que ordenem, d'acord amb el seu pes específic quantitatiu, de manera decreixent. En tercer lloc, a fi d'esbrinar en quina proporció es concentra el lèxic mariner en cadascun del poemes en què es manifesta, proporcionem una relació d'aquests per ordre decreixent d'ocurrències. En quart lloc i últim, fem una valoració de l'abast poètic que el lèxic mariner assoleix en March i n’obtenim unes conclusions.

\section{REPERTORI DEL LÈXIC MARINER DE LES POESIES D'AUSIÀS MARCH: LEMES, DEFINICIONS, VARIANTS, OCURRÈNCIES I POEMES I VERSOS EN QUÈ ES DOCUMENTEN'}

I. aigua = Mar, riu. [aygua, 3: VII, 3 ; VII,68; LXXI,56. aygu., I: II, I 8]

2. albufera = Llacuna litoral d'aigua de mar i d'aigua fluvial, tancada per un cordó de sorra. [albufera, I: CXVI, I 40]

3. anar a través = Una embarcació, anar en direcció perpendicular cap a les roques. [a travers... va, I: CIV,37]

${ }^{2}$ Leveroni fou la primera a estudiar, de manera genèrica, la funció de la mar en els poemes marquians i a establir-ne comparacions amb altres autors clàssics i medievals. Dolç revisità el tema, de manera no menys general. Ja més analíticament, Zimmermann (Ibérica) acarà les metàfores marines de March amb les de la tradició poètica medieval, i, encara, anys després (Zimmermann, $L a$ Mediterrània) retornà sobre el tema, bé que amb un enfocament més global. Deyermond va fer una proposta d'interpretació del poema II d'Ausiàs, mentre que Miralles estudià les comparacions marines del cançoner marquià. Més recentment, Torró ha proposat una nova interpretació del poema II, a partir d'una esmena textual relacionada amb el lèxic mariner. Finalment, Aguiló s'ha acostat al tema des d'una perspectiva de base etnogràfica.

3 Atès que un lema pot aparèixer també en contextos no mariners, només en constatem les variants $i$ el nombre d'ocurrències que tenen relació amb el camp semàntic objecte del nostre estudi.

4 Aquestes s'inclouen, entre parèntesis, després de cada xifra indicativa del nombre d'ocurrències d'una variant de lema. El número dels poemes va en xifres romanes i, a continuació, s'assenyala, en aràbigues, el número de vers. Totes les referències i citacions del text marquià que apareixen en aquest article remeten a l'edició revisada de Bohigas (March).

s El repertori lèxic i les definicions lexicogràfiques els fixem a partir d'Alemany; òbviament, hem tingut en compte també Alcover i Coromines. Les variants gràfiques i de flexió, així com les ocurrències, procedeixen de les concordances lematitzades esmentades a la nota $\mathrm{I}$. 
4. àncora = Instrument de fondejar, generalment de ferro, que es cala al fons de la mar i serveix per a retenir una embarcació. [àncora, I: II,4. àncores, I: LXXXII, 2]

5. arbre $=\mathrm{Pal}$ de fusta collocat verticalment en una nau, que serveix per a sostenir les vergues i les veles d'aquesta. [arbre, I: XXVII,26]

6. aturar = Parar, detenir. [aturar, 2: II,8; LXXVI, 3]

7. barca $=$ Embarcació petita de fusta, moguda a rem o a vela, emprada per a pescar, navegar a curtes distàncies, travessar rius, etc. [barca, I: CII,65]

8. born = Volta, especialment d'una nau. [born, I: XVI,43]

9. bornar = Navegar. [borna, 2: CXIII,93; CXIII, I 80. borne, I: XCII, 107]

Io. brúixola o búixola = Aparell per a determinar direccions sobre la superfície de la Terra per mitjà d'una barra imantada que gira al voltant d'un eix vertical i assenyala el nord magnètic. [brúxola, I: CXIII,205. búxola, I: CII,22]

I I. bufar = El moviment del vent, deixar-se sentir. [bufar, I: XLVI,7]

I 2. bullir el mar = La mar, estar agitada semblantment a l'aigua continguda en un recipient quan se la sotmet a cert grau de temperatura. [bullirà.l mar, I: XLVI,9]

I3. canal =Espai de mar estret situat entre dues terres properes, que comunica dues zones de mar oberta. [canal, I: CXIII,206]

I4. $\operatorname{carta}=$ Mapa, especialment l'usat en la navegació marítima, on s'indiquen els accidents geogràfics de les costes i altres detalls que orienten en la navegació. [carta, 2: XXVII,29; CXIII,205]

I 5. córrer mal temps = Passar una tempestat. [corrent, I: LXXXI,2] $\mathrm{XX}, 39]$

I6. desaferrar = Llevar l'àncora d'una nau, desancorar. [desafferre, I:

I7. do de cera $=$ Objecte de cera que es promet ofrenar a una imatge religiosa per un benefici rebut, exvot. [dons de cera, I: XLVI, I 8]

18. donar la vela = Posar-se a navegar. [dóna la vela, I: XX,36]

19. ensenya = Senyal que serveix al navegant de punt d'orientació. [ensenyes, I: XCVIII,3]

20. entrar en la mar = Engolfar-se, endinsar-se en la mar. [entra.n la mar, I: CII,68]

2I. escandall = Instrument format per una peça de plom posada a l'extrem d'una corda, que serveix per a determinar la profunditat de la mar, d'un riu, etc., en un punt determinat. [escandall, 3: XXVI,57; LXXVI,3; CXXVIII, 599]

22. estrop = Corda o corretja que es lliga a l'art de pescar per a traure'l a la platja. [estrob, i: CXXVIIb,26]

23. far = Torre situada en llocs ben visibles de les costes, amb un llum en la part superior que serveix per a guiar de nit els navegants. [far, I: CXXII,29] ${ }^{6}$

24. ferro $=$ Àncora petita i sense cep. [ferre, $\mathrm{I}: \mathrm{XX}, 38]$

${ }^{6}$ Només documentat, de manera lexicalitzada, en el topònim Far, amb el qual el poeta alludeix al far de Messina. 
25. fons = Superfície sòlida sobre la qual es troba l'aigua de la mar, d'un riu, d'un estany. [fons, 4: XXVI,58; LIX, i 8; LXXVI,3; CXXVIII,600]

26. fortunal [referit al vent] = Tempestuós. [fortunal, I: II,9]

27. fusta $=$ Embarcació feta de fust. [fusta, 2: LXXXII, I; CIV,37]

28. galera $=$ Antic vaixell llarg, estret i relativament baix, que, tot i que comptava amb veles auxiliars, tenia com a element principal de propulsió més de trenta rems per banda, cadascun dels quals manejaven dos o tres galiots. [galera, I: CXIII, I 39]

29. golf = Alta mar. [golf, $\mathrm{r}: \mathrm{XXVII,25]}$

30. governador $=$ Timó per a dirigir una nau, governall. [governador, I: XXVII,26]

3 $\mathrm{I}$. grec $=$ Vent que ve del nord-est, gregal. [grech, $\mathrm{I}: \mathrm{XLVI}, 5]$

32. llevant $=\mathrm{Vent}$ que ve de l'est. [levant, $\mathrm{I}: \mathrm{XLVI}, 4]$

33. mar $=$ Massa d'aigua salada que cobreix una gran part de la superfície de la Terra. [mar, I7: IV,9; XVIII,43; XX,40; XXVI,47; XXVII,33; XLVI,2; XLVI,I5; LXIX,27; LXXXI,2; C,58; CII,I7; CIV,73; CV,I33;CXVI,I39; CXIX, I9; CXXVIII,289; CXXVIII,602]

34. marea $=$ Moviment alternatiu d'ascens i de descens del nivell de les aigües de la mar, degut a les atraccions combinades de la Lluna i del Sol. [marea, I: LXXXVII,92]

35. mariner $=$ Tripulant d'una embarcació. [mariners, 2: XXVII,28; LXXIV, I 8]

36. mestre $=$ Vent que ve del nord-oest, mestral. [mestre, $\mathrm{I}: \mathrm{XLVI}, 3]$

37. migjorn $=$ Vent que ve del sud. [migjorn, $\mathrm{I}: \mathrm{XLVI}, 5]$

38. nadar = Sostenir-se $\mathrm{i}$ avançar dins l'aigua per mitjà de certs moviments dels braços i de les cames. [nadant, I: CXXb,76; nade, I: CV,66]

39. nau = Embarcació sense rems, generalment de tres pals, de buc molt alt, amb castell de proa, moguda pel vent amb ajuda de veles. [nau, 6: II,2; XXVII,25; LXXIV, I 7; LXXIV,r 9; CXIII, I 80; CXXVIII,394]

40. nauxer $=$ Mariner d'alta graduació que dirigia la maniobra d'un vaixell. [naucher, I: CIV,38]

4I. navegar = Anar, viatjar en una embarcació. [navegar, 2: CXXVIII,293; CXXVIII,606; navegen, I: CIV,73; navegua, I: C,5] $\mathrm{XX}, 40]$

42. negar = Asfixiar per immersió en un líquid. [negar, I: CII,72. negat, I:

43. ofegar $=$ Fer morir privant la respiració. [offegats, I: CXXVIII,602]

44. ormeig $=$ Conjunt de cordes, veles $\mathrm{i}$ altres estris destinats al govern $\mathrm{i}$ moviment d'una nau. [ormeig, I: LXXXII,2]

45. patró $=$ Individu que comanda una embarcació. [patró, I: II,I]

46. peix $=$ Animal vertebrat aquàtic de cos fusiforme, generalment comprimit als costats o pla, i acabat en una aleta ampla vertical, la pell coberta d'escates, les extremitats, quan en té, en forma d'aletes, l'esquelet cartilaginós, la respiració branquial, la temperatura variable i la reproducció ovípara. [peix, 2: II, I7; CII,66.peixs, I: XLVI, I3] 
47. pilot $=$ Individu que guia una nau en marxa. [pilot, I: CXIII,206]

48. platja $=$ Vorera sedimentària i planera de la mar, d'un llac o d'un riu gran, formada generalment de sorra o de grava. [plaga, I: LXXVI,6; plaja, I: XCII, 57; platga, I: II, I]

49. ponent $=$ Vent que ve de l'oest. [ponent, $\mathrm{I}$ : XLVI,3]

50. port $=$ Abric natural o artificial en una costa o en una vora de riu, on les embarcacions poden amarrar. [port, 10: XVI,32; XX,4; XX,37; XX, 38; XX,39; LX,36; LXXVI,4; LXXXII,2; XCII, 57; CXXVII,57. ports, I: II,8]

5. proejar el temps = Anar contra el corrent de les ones, contra la direcció del vent. [proejant lo temps, I: LXXIV,24]

52. riba $=$ Vora de la mar, d'un riu o d'una altra gran extensió d'aigua. [riba, I: XCVIII,4]

53. riu $=$ Corrent natural d'aigua dolça procedent de les muntanyes, que aflueix a la mar, a un llac o a un altre corrent. [riu, 4: VII,67; LXXI,56; LXXXVI,9; CII,65. rius, 2: CV,133; CXIX,19]

54. roca $=$ Massa de pedra de gran volum que sol sobreeixir de la superfície de la terra o de la mar. [roca, I: CIV,37]

55. sardina $=$ Peix de la família dels clupeids, d'uns 20025 centímetres de llargària màxima, amb l'esquena de color verd blavós, els costats i el ventre argentats, i el cos cobert d'escates grosses. (Sardina pilchardus). [sardina, I: C,40]

56. senya $=$ Senyal que serveix al navegant de punt d'orientació. [senya, I: LXXIV,20]

57. tempesta $=$ Tempestat. [tempesta, $\mathrm{I}:$ LXVIII, 17$]$

58. tempestat $=$ Pertorbació intensa de l'estat atmosfèric que es manifesta en fenòmens meteorològics tals com el vent, la pluja, la neu, la pedra, els llamps i els trons [tempestat, I: II,6]

59. temporal $=$ Tempestat, especialment a la mar. [temporal, I: II,5]

60. temps = Estat atmosfèric, oratge. [temps, 8: II,6; XXXIV,34; LXVIII, 17; LXXXIV,23; XC,9; CI,5 I; CXIII,249; CXX, I 2 I]

6r. terra $=$ Part sòlida de la superfície de la Terra, en contraposició a la mar. [terra, 3: XXVII,3 I; XLVI, 16; LXIX,27]

62. tramuntana $=$ Estel polar que indica el nord i servia de punt d'orientació als mariners. [tremuntana, I: CIV,74]

63. vela $=$ Tros de lona o de tela forta format generalment de diferents peces cosides, que se subjecta a l'arbre, a les vergues o als estais d'una nau per a rebre l'impuls del vent i fer que aquest la faça córrer. [veles, I: XLVI, I]

64. vent $=$ Moviment natural, generalment horitzontal, de masses d'aire. [vent, II：II,9; IV,I2; XXVII,32; XXXIV,5; XLVI,6; LXXVI,5; XC,10; XCII,195. XCVIII,8; CIII,I 80; CVIII,64. vents, 7: IV,Io; XX,36; XXVII,27; XLVI,I; LXXIV, i 7; C,6; CXXVII,56]

65. vent de Tramuntana $=$ Vent que ve del nord. [vent de Tremuntana, I: XCVIII,8]

66. vent tramuntanal $=$ Vent que ve del nord. [vent tremuntanal, $\mathrm{I}$ : XLVI,6] 
67. $x a l o c=$ Vent que ve del sud-est. $[x a l o c h, \mathrm{I}: \mathrm{XLVI}, 4]$

Aquests seixanta-set lemes suposen el 2,0 I \% del vocabulari total de les poesies d'Ausiàs i es manifesten en vuitanta-una variants gràfiques o de flexió (l'ı,02\% de les de la totalitat del poemari) documentades en cent cinquantatres ocurrències (el 0,19\% de les del conjunt del corpus).

\section{Classificació del RePERTORI LÈXic Mariner Marquià EN SUBCAMPS SEMÀNTICS, PER ORDRE DECREIXENT DE PRESÈNCIA QUANTITATIVA DE LEMES}

I. Fenòmens meteorològics relacionats amb la navegació i amb la mar (setze lemes $=23,88 \%)^{7}$ : bufar, bullir la mar, fortunal [referit al vent], grec, llevant, marea, mestre, migjorn, ponent, tempesta, tempestat, temporal, temps, vent, vent de tremuntana, vent tramuntanal i xaloc. ${ }^{8}$

2. Accions relacionades amb la navegació o amb la mar (tretze lemes = I9,40 \%): anar a través, aturar, born, bornar, córrer mal temps, desaferrar, donar la vela, entrar en la mar, nadar, navegar, negar, ofegar i proejar el temps.

3. Estris útils per a la navegació (nou lemes $=\mathrm{I}_{3}, 63 \%$ ): ancora, arbre, brúixola o búixola, carta, escandall, ferro, governador, ormeig i vela.

4. Elements de la natura, geològics o artificials relacionats amb la navegació (deu lemes = I4,92 \%): ensenya, far, fons, platja, port, riba, roca, senya, tremuntana i terra.

5. Espais maritimofluvials relacionats amb la navegació (sis lemes $=8,95$ $\%)$ : aigua, albufera, canal, golf, mar i riu.

6. Embarcacions (quatre lemes $=5,97 \%$ ): barca, fusta, galera i nau.

7. Tripulació (quatre lemes $=5,97 \%$ ): mariner, nauxer, patró i pilot .

8. Pesca (tres lemes $=4,47 \%$ ): estrop, peix i sardina.

9. Elements antropològics relacionables parcialment amb la navegació (un lema $=\mathrm{I}, 49 \%$ ): do de cera.

\section{GRUPS DE POEMES EN QUÈ ES DOCUMENTEN OCURRÈNCIES DEL LÈXIC MARINER, ORDENATS PER ORDRE DECREIXENT}

$$
\text { D'AQUESTES }
$$

a. Un poema amb setze ocurrències: XLVI [veles (v. I), vents (v. I), mar (v. 2), mestre (v. 3), ponent (v. 3), xaloch (v. 4), levant (v. 4), grech (v. 5), migjorn

7 Tant aquest percentatge com els que segueixen en aquest apartat s'obtenen prenent com a referència els seixanta-set lemes de l'àmbit mariner i no la totalitat del vocabulari poètic marquià.

${ }^{8}$ Els mots núvol, ploure, tro i rellamp, també pertanyents a l'àmbit meteorològic, en March no apareixen en contextos nàutics. 
(v. 5), vent tremuntanal (v. 6), bufar (v. 7), bullirà.l mar (v. 9), peixs (v. I3), mar (v. I 5), terra (v. I6), do de cera (v. I8)].

b. Un poema amb tretze ocurrències: II [patró (v. I), platga (v. I), nau (v. 2), àncora (v. 4), temporal (v. 5), tempestat (v. 6), temps (v. 6), ports (v. 8), aturar (v. 8) vent (v. 9), fortunal (v. 9), peix (v. I7), aygu (v. I 8)].

c. Dos poemes amb deu ocurrències: Xx [port (v. 4), vents (v. 36), dóna la vela (v. 36), port (v. 37), port (v. 38), ferre (v. 38), port (v. 39), desafferre (v. 39), mar (v. 40), negat (v. 40)] i XXVII [nau (v. 25), golf (v. 25), arbre (v. 26), governador (v. 26), vents (v. 27), mariners (v. 28), carta (v. 29), terra (v. 3 I), vent (v. 32), $\operatorname{mar}($ v. 33)].

d. Un poema amb nou ocurrències: cxiII [borna (v. 93), galera (v. I39), nau (v. I 80), borna (v. I 80), brúxola (v. 205), carta (v. 205), pilot (v. 206), canal (v. 206) temps (v. 249)].

e. Un poema amb vuit ocurrències: CXXVIII [mar (v. 289), navegar (v. 293), nau (v. 394), escandall (v. 599), fons (v. 600), mar (v. 602), ser offegats (v. 602), navegar (v. 606)].

f. Dos poemes amb set ocurrències: CII [mar (v. I7), búxola (v. 22), barca (v. 65), riu (v. 65), peix (v. 66), entra.n la mar (v. 68), negar (v. 72)] i cIv [a travers... va (v. 37), fusta (v. 37), roca (v. 37), naucher (v. 38), mar (v. 73), navegen (v. 73), tremuntana (v. 74)].

g. Un poema amb sis ocurrències: LxxIv [vents (v. I7), nau (v. I7), mariners (v. I 8), nau (v. I9), senya (v. 20), proejant lo temps (v. 24)].

h. Un poema amb cinc ocurrències: LXxvi [escandall (v. 3), fons (v. 3), port (v. 4), vent (v. 5), plaga (v. 6)].

i. Dos poemes amb quatre ocurrències: LXXXII [fusta (v. I), port (v. 2), àncores (v. 2), ormeig (v. 2)] i c [navegua (v. 5), vents (v. 6), sardina (v. 40), mar (v. 58)].

j. Sis poemes amb tres ocurrències: Iv [mar (v. 9), vents (v. IO), vent (v. I2)], vir [aygua (v. I3), riu (v. 67), aygua (v. 68)], XXvi [mar (v. 47), escandall (v. 57), fons (v. 58)], XCII [port (v. 57), platja (v. 57), vent (v. I95)], XCVIII [ensenyes (v. 3), riba (v. 4), vent de Tremuntana (v. 8)] i cxxvi [estrop (v. 26), vents (v. 56), port (v. 57)].

k. Dotze poemes amb dues ocurrències: Xvi [port (v. 32); pren born (v. 43)], XXXIV [vent (v. 5), temps (v. 34)], LXVIII [temps (v. I7), tempesta (v. I7)], LXIX [terra (v. 27), mar (v. 27)], LXXI [aygua (v. 56), riu (v. 56)], LXXXI [corrent mal temps (v. 2), mar (v. 2)], xc [temps (v. 9), vent (v. Io), cI [temps (v. 5 I)], cv [nade (v. 66), riu (v. I 33)], CXvi [mar (v. I 39), albufera (v. I 40)], CXIX [mar (v. I9), rius (v. 19)] i cxxirb [far (v. 29), nadant (v. 76)].

1. Deu poemes amb una sola ocurrència: XviII $[\operatorname{mar}(\mathrm{v} .43)]$, XxxviII [pren born (v. 40)], LIX [fons (v. I 8)], LX [port (v. 36)], LXXXIV [temps (v. 23)], LXXXVI [riu (v. 9)], LXXXviI [marea (v. 92], CIII [vent (v. I 80)], CviII [vent (v. 64)] i CXX [temps (v. I $2 \mathrm{I})]$.

De tot plegat, es dedueix que la totalitat d'ocurrències del lèxic mariner es concentra en quaranta poemes (el 3 1,25\%) dels cent vint-i-vuit acceptats gene- 
ralment per la crítica com a constitutius del cànon ausiasmarquià. Al seu torn, de les cent cinquanta-dues ocurrències lèxiques que contenen aquestes quaranta composicions, el I0,459\% convergeix en la poesia XLVI; el 8,49\% en la II; un $6,53 \%$ en cadascun del poemes xx i xxvir; el 5,88 \% en el cxiII; el 5,22\% en el CXXviII; un 4,57\% en cadascuna de les composicions cII i cIV; el 3,92\% en la LXXIV; el 3,26 \% en la LXXVI; el 2,6I \% en cadascuna de les poesies LXXXII i c; un I,96 \% en cadascun dels poemes IV, VII, XXVI, LXXI, XCII i CXXVII; un I, $30 \%$ en

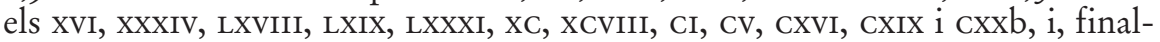
ment, un $0,65 \%$ en cadascuna de les poesies XVIII, XXX, XXXVIII, LIX, LX, LXXXIV, LXXXVI, LXXXVII, CIII, CVIII i CXX.

\section{Dimensió poètica I VAloració conclusiva}

El vocabulari mariner, quantitativament, té una presència bastant limitada en el poemari marquià. Les freqüències dels seixanta-set termes que l'integren no permeten considerar-los com a mots clau de l'obra, a diferència del que ocorre amb paraules com amor, yo, delit, dolor... (Hauf I26-I3 I). Tot i això, amb aquest repertori lèxic el poeta crea unes imatges literàries impactants que esdevenen un ingredient qualitativament important del seu cançoner (Zimmermann, La Mediterrània 54).

El principal element referenciat és la mar, la massa d'aigua salada per on s'han de desplaçar els navegants i que en March és sempre turbulenta: «El mar i sobretot el mar en tempesta, és el seu símbol feliç, la clau del seu món poètic, del seu món autèntic» (Leveroni I 53). ${ }^{9}$ La mar hi assoleix el paper de metàfora de les turmentoses quimeres del jo líric perquè és tan incerta i perillosa com elles: «Tals com aquells qui per la mar navegen / són desviats si·ls fall la tremuntana, / e van en loch on la venture·ls porta, / són en lo món los hòmens qu·en ell viuen» (CIV 73). El desig de palesar les passions que lluiten dins l'esperit és el que justifica els dos moviments marins esmentats en l'obra: bullir la mar i la marea. Especial importància té l'accepció marinera del verb bullir en aquest context, que no és altra que la de "moure's agitadament la mar": «Bullira.l mar com la caçola·n forn» (XLVI 9)..$^{\text {I0 }}$ Altrament, el vocable marea $^{11}$ és emprat per a simbolitzar les oscillacions de la voluntat (LXXXVII 92).

A aquests mots, amb els quals es conformen imatges del moviment anímic del jo poètic, se n'hi han d'afegir encara d'altres que expressen els entrebancs que interfereixen la seua experiència vital. Són tempesta, tempestat i temporal,

${ }_{9}$ Aquest terme apareix dinou vegades, dues de les quals en els fraseologismes bullir el mar $\mathrm{i}$ entrar en la mar.

${ }^{10}$ Es tracta d'una imatge de gran fortuna literària (Leveroni; Zimmermann, La Mediterrània), i que, a més, encara s'usa per mariners mallorquins (Aguiló I7-I9) i valencians.

${ }^{I I}$ Terme poc popular, aleshores, i d'ús restringit entre capes socials illustrades (Coromines V 458 b). Tot i que Coromines el documenta per primera vegada en March, Jal n'arreplega una citació anterior de l'Atles d'Abraham Cresques i Jafudà Cresques (I 375 ). 
tots tres relacionats amb el sentit meteorològic de temps, que connoten les circumstàncies adverses del devenir marí: «Axí com cell qui·s veu prop de la mort, / corrent mal temps, perillant en la mar» (LXXXI 2). Són els senyals que preparen el desenllaç tràgic expressat pels verbs negar i ofegar (CXXVIII 602). ${ }^{\text {I2 }}$ Qui sobrevivia a un tràngol d'aquesta mena sovint feia una ofrena als déus que es materialitzava en els exvots de cera, als quals també alludeix el poeta (XLVI I7-I 8). ${ }^{\mathrm{I} 3}$ Relacionada amb aquestes circumstàncies negatives, trobem l'expressió anar a travers: «si a travers la fusta v•a la roca / rahó serà puys naucher no la guia» (CIV 37). Així mateix, en la mateixa línia de la perillositat de la navegació, s'hi documenta l'expressió entrar en la mar en època no propícia: "per esser de béns pus abundós / entra·n en la mar e no y espera stiu» (CII 68). ${ }^{{ }^{14}}$ La navegació medieval depenia totalment del vent i de l'onatge; per tant, els mesos d'estiu eren els únics que permetien aquesta activitat. ${ }^{\text {is }}$

Davant d'aquestes situacions, el poeta centra la seua selecció lèxica en termes de govern i fermança del vaixell, com àncora, arbre, ferro, governador, ormeig i vela, objectes la destrucció dels quals abocava els nautes a l'abisme: "Yo contrafaç nau en golf perillan, / l'arbre perdent e son governador» (XXVII $25)$. En aquest mateix poema, dos vents bufen de manera contrària $i$, en conseqüència, la nau no avança: «e per contrast de dos vents no discor» (XXVII 27), situació que genera el debat entre els tripulants: «los mariners enbadalits estan, / e cascú d'ells la sua carta tenta, / e són discorts en llur acordament» (XXVII 28-30) (Zimmermann, La Mediterrània 54). Al pol positiu, trobem les veles $\mathrm{i}$ els vents, que són els mitjans per a aconseguir l'objectiu del jo líric: «Veles e vents han mos desigs complir» (XLVI r).

El lèxic mariner de March també informa de diverses classes d'embarcació com la barca, la fusta, la galera i la nau. Són les grans embarcacions del segle xv, a excepció de la barca que, no per casualitat, està qualificada amb l'adjectiu flaca: «Sí com aquell qu·ab flaca barca·n riu / pesca son peix» (CII 65). ${ }^{16}$ Quant al terme fusta, tot i que llavors podia referir-se a una mena de galera petita, en l'ús marquià és un hiperònim acordat a la llengua del seu temps. Al seu torn, la nau i la galera —aquesta última molt citada en la bibliografia nàutica sobre la

${ }^{12}$ El naufragi, la probabilitat quasi certa de la mort, marcava i marca profundament l'ànim dels navegants. És per això que, sovint, esdevingué tabú i tendí a substituir-se pel verb perdre's. Un exemple d'aquest procés el trobem ja reportat al Liber Elegantiarum: «Algunes naus forts han donat a través o són perdudes» (Esteve 78 ).

${ }_{13}$ Precisament, el model més antic conservat d'una nau, coetània d'Ausiàs March, és un exvot que hi havia a l'ermita de Sant Simó de Mataró (Winter 7).

${ }^{14}$ March es refereix ací a la navegació de grans embarcacions. «Ésta es otra de las razones de la navegación estival de los grandes mercantes (mare apertum, desde mayo hasta septiembre, aunque los más arriesgados la prolongaban de marzo a octubre o noviembre)» (Espinosa, Sáez, Castillo 7).

is March, bon coneixedor de la navegació del seu temps, remarca el risc de navegar fora del període estival, una circumstància que el refranyer recull: «Passats els Dolors, barques al secador, $\mathrm{i}$ per Sant Marc, altra vegada en mar». Vegeu també Anton (32).

${ }^{16}$ A l'època de March, el terme barca podia designar diverses classes de vaixell, fins i tot velers d'alta borda d'entre vint $\mathrm{i}$ cent tones, però no és el cas que documenta el poeta (Guiral-Hadziiossif 50). 
València del segle xv (Guiral-Hadziiossif 56) — eren les senyores de la mar. La condició majestuosa de la primera ve refermada per l'adjectiu gran i la comparació amb un castell: «Pren-me’n axí com al patró qu·en platga / té sa gran nau e pens-aver castell» (II 2). Altrament, la galera és alludida per una de les seues característiques més peculiars, la ferum que emanava i que es podia olorar a quilòmetres de distància: «axí com l'hom que viu en la galera, / que ja pudor l'és olor falaguera» (CXIII I 40). ${ }^{17}$

El lèxic relacionat amb els moviments de la nau conté els verbs aturar, bornar, desaferrar, proejar, navegar, i també els ja esmentats negar, afonar i anar a travers. Desaferrar i navegar són verbs mariners usuals en els registres literaris, contràriament a proejar, "navegar contra el vent de proa o contra el corrent", que, generalment, només apareix en els derroteros i llibres de nàutica dels segles XVI i XVII. ${ }^{18}$ Amb el verb, derivat de proa, "part davantera de l'embarcació", es reforça el sentit d'acarament, d'enfrontament, de lluita: «determenar llur debat clar no gos, / proejant lo temps, l'appetit vaig siguent» (LXXIV 24). Tanmateix el llenguatge literari quatrecentista feia un ús preferent de l'expressió quasi sinònima anar a l'orsa (o a orsa) per a expressar els efectes perniciosos del vent contrari, com veiem en Lo passi en cobles: "yo us dich, o! juheus, que no veig que torça / lo viure d'aquest, ni va gens a l'orça / a pendre lo port de salvació» (Garcia 282). March potser tenia més de noble feudal que de navegant i, per això, malgrat els referents navals de certes imatges, podem observar que el cavaller se superposa al nauta quan parla de bornar per a referir-se a les bordades de la nau: «Lo mal és bé, e lo bé mal retorna: / algú no sab sa nau per quin vent borna» (CXIII I80). Entre les accions per a traslladar-se dins del medi marí, el poeta empra el verb nadar en un sentit hiperbòlic, no exempt d'humor, quan, arrossegat pel deler d'obtenir un falcó, manifesta el desig d'arribar nadant a Nàpols: «per demostrar com ne per què u he fet / si m'és manat, yo passaré nadant» (CXXIIb 76).

Els termes referits als tripulants de la nau són mariner, nauxer, patró i pilot. Una enumeració curta que presenta el collectiu mariners discutint sobre el rumb adequat de la nau (XXVII 28-30). Amb els mots de caràcter individual, nauxer, patró i pilot, s'allludeix a tres càrrecs importants del guiatge de les embarcacions, sense la intervenció dels quals aquestes podien anar a la deriva i acabar destruïdes: «Si a travers la fusta va [a] la roca, / rahó serà puys naucher

${ }^{17}$ «Una vegada a la galera, el galiot era encadenat al seu banc on romandria sense moure's fins arribar a un nou port. En el mateix indret, és a dir en el seu banc, remava, menjava, dormia... i inclús feia les seves necessitats, que ni per a això eren deslligats ... No és estrany que amb la manca d'higiene dels prop de 400 homes que treballaven al veler, la pudor de les galeres es fes cèlebre arreu. Per a poder-ho suportar, els oficials tenien un perfumista que ruixava contínuament l'aire amb essències, però era gairebé impossible eliminar la fetor de l'ambient. Degut a aquesta insuportable fortor, les galeres no podien comptar amb el factor sorpresa per a realitzar un atac, perquè se les olorava de lluny» (Mayolas 25).

${ }^{18}$ Els derroteros, regimientos de navegar, artes de navegar... tenen un esplet a partir de les exploracions del continent americà i són escrits en castellà. Tot $i$ això, hi trobem força terminologia catalana com proejar (Nieto I I I). 
no la guia» (CIV 37-38). Per altra part, els responsables de la navegació compten amb una sèrie d'estris que faciliten l'orientació com la búixola (o brúixola) ${ }^{19}$ i la carta (de navegar), o d'altres que permeten esbrinar la fondària de la mar i la composició del sòl marí, com l'escandall, sense oblidar-nos de la principal guia millenària que fou l'estel de tramuntana: «Tals com aquells qui per la mar navegen / són desviats si.ls fall la tremuntana» (CIV 74).

A més dels mots mar o aigua, March n'usa d'altres al-lusius als escenaris de la navegació i amb els elements geomorfològics que hi són relacionables: canal, escull, fons, golf, port, platja, roca, riba; tot plegat en contraposició absoluta amb la terra, que és vista com a lloc de salvació enmig de la tempesta: «hu volgra sser prop terra passos cent» (XXVII 3 I). És el mateix valor positiu que s'hi atribueix al terme port, concebut com el recer segur: «port molt desitjat» (XX 37), «segur port» (LXXXII 2), «bon port» (XX 4).

Entre la mar i la terra se situen els elements de transició entre els dos medis, com l'albufera, la platja i la riba. El mot platja apareix sempre com a recer insegur i solitari -en oposició a port-, concepte que reforça en algun cas l'adjectiu deserta: «cuyd.haver port en la plaja deserta / e lo verí li sembla medecina» (XCVII 57); "Lo que, dabans, de tot vent me guardava / és envers mi cruel plaga deserta» (LXXVI 7). El mateix sentit negatiu tenyeix també el vocable riba $a^{20}$ —só avengut a perillosa riba» (XCVIII 4) -, així com el mot escull - usat ací en sentit translatici, però originàriament terme mariner (CI 19)Als antípodes, constatem el terme ensenya, senyal que serveix de punt d'orientació. ${ }^{21}$

Quant a la toponímia, hem d'indicar que és poc present en el poemari marquià, tret de les allusions al Far i a la canal de Flandes, dos importants punts de referència en la navegació medieval. El primer al-ludeix a l'antic far de Messina, que donava la benvinguda a la península Itàlica; el segon és el canal de la Mànega, pas obligat per a les galeres que feien la navegació atlàntica nord-europea, la perillosa travessa del qual requeria personal molt destre: «Ell va de nit sens brúxola o carta / menys de pilot, en la canal de Flandes» (CXIII 206).

$\mathrm{Al}$ cançoner marquià, encara apareixen altres termes del lèxic mariner. Així, dins l'àmbit de la pesca, trobem l'estrop, "tros de corda o corretja que es lliga a l'art de pesca per a traure'l a la platja” — «en sofirença no só Job, / ans volria tirar l'estrob» (CXXVII 26) - , mot usat també, en contextos semblants, en altres obres valencianes del segle Xv com ara l'Espill de Jaume Roig (v. 2 I86): «Mala em prenguist / per a tos ops! / Tirar los strops / sabries més!». Així mateix, relacionat amb la pesca, es documenta el lèxic de la fauna marina, molt minsament representat pel genèric peix i pel particular sardina.

\footnotetext{
${ }^{19}$ Coromines (II 296a) afirma que la variant que degué usar March fou búxola, forma etimològica, i que brúxola — amb repercussió de líquida - es deu als copistes.

${ }^{20}$ També es documenta en March (LXVIII: 26) el derivat ribatge, però fora del context mariner.

${ }^{21}$ És viu i general entre els mariners i els pescadors valencians el terme senya -que suposem variant aferètica d'ensenya.
} 
Contràriament, sí que té una importància notable el lèxic eòlic: fortunal, grec, llevant, mestre, migjorn, ponent, tremuntana, tremuntanal, vent i xaloc, a banda dels ja esmentats temps i derivats. Les denominacions dels vents es concentren al poema XLVI, on es descriu una tempesta que conforma una imatge poètica molt ben fonamentada en l'observació de la natura, com demostra el fet que, encara avui, mariners que conegueren la navegació a vela, ens en donen testimoni (Llorca $174-175) .{ }^{22}$ Tanmateix, sobta l'estranya absència del llebeig o garbí en tot el corpus marquià. ${ }^{23}$ Quan al vent fortunal o desfavorable - amb l'adjectiu derivat de fortuna, entesa com a "tempesta"-, cal indicar que es tracta d'una expressió molt comuna en la poesia medieval mediterrània (Vidos 402). ${ }^{24}$

Arribats en aquest punt, cal advertir que, si, com hem vist, el nombre de mots pertanyents al lèxic mariner varia molt d'uns poemes a uns altres, també la dimensió poètica d'aquest difereix segons les composicions, de manera que, mentre en alguna constitueix el nucli temàtic cardinal, en d'altres serveix per a la construcció de símils, metàfores o allegories que ocupen una part més o menys significativa del poema. No hi manquen tampoc les poesies en què l'ús de mots del camp semàntic mariner és purament ocasional i denotatiu, aliè a qualsevol tipus de funció poètica rellevant. Ho veurem tot seguit.

El poema XLVI, que presenta el major nombre d'ocurrències de lèxic mariner - setze-, se'n serveix per a ordir la narració d'una hipotètica situació de risc extrem viscuda pel jo líric, que, tanmateix, lluny de portar-lo a oblidar l'amor per la seua dama, el mena a reafirmar-s'hi fins i tot més enllà de la mort que li puga sobrevenir. El jo poètic, allunyat de l'amada, es disposa a fer la travessa marítima que el retornarà a ella amb l'ajut de les veles i de la combinació propícia dels vents. En aquest context, imagina la possibilitat que sobrevinga una tempesta — «bullirà el mar com a cassola en forn»- d'una magnitud tan gran que farà que els peixos vagen a protegir-se a la terra i que els tripulants, preocupats per la seua supervivència, facen tota classe de prometences, oferiments d'exvots i confessió pública dels seus pecats més recòndits. Aquesta apocalíptica situació no obstarà perquè el jo líric mantinga viu l'amor per l'estimada fins $\mathrm{i}$ tot en el cas de perdre la vida. És evident, doncs, que en aquest poema l'enfilall d'abundants termes mariners s'incardina en la narració d'un fet imaginat com és la navegació a la recerca de l'amada — clara reelaboració del tòpic de la navegació amorosa- entrebancada per una tempesta. Navegació i tempesta esdevenen, doncs, els motius nuclears que justifiquen l'abundant presència de mots del camp semàntic mariner, que, a més de constituir el material de construcció fonamental de l'eix narratiu, forneixen ensems riques imatges, com ara

${ }^{22}$ També els regimientos expliquen aquesta circumstància, però d'una manera més tècnica (Medina LIX).

${ }^{23}$ Per a la interpretació de la primera cobla del poema XLvi, vegeu Zimmermann, La Mediterrània, 57.

${ }^{24}$ Cal dir que tenim altres exemples de vocables que han seguit la seua expansió per via poètica, tal com també constata la lexicografia per al terme castellà escollo, "escull”, poc usual en aquesta llengua (o en portuguès) en la qual té un regust literari i cultista (Coromines III 563b-564a). 
la personificació aplicada al tractament de l’acció cooperativa dels vents o la metàfora «bullirà el mar».

Ben diferentment, les tretze ocurrències de mots mariners del poema II forneixen un símil mitjançant el qual el jo líric explica les contradiccions entre el plaer que li causa el seu estat d'enamorament i el dolor suscitat per la por que es frustren les seues expectatives amoroses (Deyermond 83). El jo poètic s'identifica amb un patró que té ancorada una gran nau a la platja oberta, confiat que, pels indicis que ofereix l'oratge, pot estar segur de no córrer cap risc, però que, davant d'un sobtat temporal, es veu obligat a dirigir-se a algun port segur on es puga preservar millor.

$\mathrm{Al}$ seu torn, les deu paraules marineres documentades tant al poema XX com al xxvir possibiliten la creació de sengles petites al-legories, localitzades en les estrofes cinquena i quarta de cadascuna d'aquestes composicions, respectivament. En el primer cas, el desig del jo poètic el fa navegar — «als vents dóna la vela»— en direcció cap «al port molt desijat» de la seua amada, únic en què vol fermar l'àncora — «lo ferre»—, ja que, si no ho fa allí, morirà: «e si del tot del port me desaferre, / en esta mar me trobaré negat». En el segon cas, un jo líric ple de contradiccions provocades per l'experiència amorosa s'identifica amb una nau que, atrapada per vents contraris, perilla en alta mar - el «golf»- a causa d'haver perdut el timó —el «governador»— i el pal major —l'«arbre»—, mentre la tripulació es debat en opcions dispars a l'hora de superar la situació plantejada (Leveroni i 52).

La composició cXIII - 254 versos- desenvolupa el tema de la incapacitat de l'ésser humà per a discernir quin és el veritable bé, cosa que li fa considerar com a tal els falsos béns mundans i allunyar-se de la virtut. En aquest cas, els nou vocables del camp semàntic mariner que hi apareixen s'aprofiten en cinc punts diferents del poema. En el primer (v. 193), amb el verb «bornar» — «entre ver i fals borna»- s'alludeix a l'itinerari incert a què ens condueix l'impuls irracional dels apetits instintius. El segon (v. I39-I40), incorpora el mot «galera» a un símil mitjançant el qual es compara la incapacitat humana per a identificar el mal, a força de conviure amb ell, amb el que s'esdevé en «l'hom que va en galera, / que ja pudor l'és falaguera». En el tercer punt (v. I80), es torna a insistir en la desorientació moral dels humans amb la imatge "algú no sab sa nau per quin vent borna». Al seu torn, el quart punt (v. 205-206), reitera la idea nuclear del poema mitjançant la identificació de l'ésser humà amb el pilot d'un vaixell que, de nit, sense brúixola ni carta de navegació, gosa travessar les perilloses aigües del canal de la Mànega. Finalment, en el cinquè i últim punt (vers 249), el mot temps - “oratge”- s'incorpora a un símil segons el qual, així com el temps humit implica l'existència del temps sec, «els fets del món van de bon'obr·a a mala».

En un altre extens cant, el cxxvin -695 versos-, les vuit ocurrències de lèxic mariner de què consta es distribueixen en tres seqüències, de les quals només una (v. 599-606) transcendeix el pur sentit recte $\mathrm{i}$ assoleix un valor simbolicoalllegòric: la vida terrenal i els seus béns s'identifiquen amb una mar 
profunda i perillosa, per a esbrinar el fons de la qual no cal cap escandall, ja que l'evidència palesa que qualsevol que intente transitar-la acaba ofegant-s'hi.

Dos poemes més, el CII -230 versos- i el CIV -288 versos-, contenen, en cada cas, set exponents de lèxic mariner. En el primer, es concentren en dues seqüències que abracen, respectivament, els versos 17-22 i 65-72. La primera d'aquestes seqüències constitueix un símil en què el jo líric, frustrat per haver caigut en l'amor baix que tant havia blasmat com a teòric singular de l'amor sublim, es compara amb un mariner que, malgrat ser molt experimentat, pot arribar a errar el rumb davant d'unes circumstàncies imprevistes. La segona seqüència conforma també un altre símil mitjançant el qual es compara aquell que cerca en «dona vil» quelcom més que la carnalitat amb l'humil pescador que, en comptes d'acontentar-se amb la limitada pesca de riu, s'arrisca a endinsarse en alta mar, sense mirar el perill, amb l'objectiu d'obtenir uns resultats més abundosos. La composició cIV també aglutina els mots de l'àmbit mariner en dues seqüències: en la primera (v. 37-38), l'individu que no es regeix per la virtut i que, per tant, va camí de perdició, és identificat amb la nau que, sense la direcció del nauxer, s'estavella contra les roques; en la segona (v. 73-74), tots els qui no es regeixen per la virtut, sinó pels apetits, són comparats amb els navegants que perden el nord, l'orientació, i que, en conseqüència, van a la deriva.

En la composició LXxiv, on es concentren sis ocurrències lèxiques de caire mariner (v. 17-24), el jo líric, procliu als plaers del cos, es debat entre l'amor espiritual i el carnal, però, mentre resol, opta per seguir lliurant-se a aquest últim. Per a illustrar aquesta situació, es recorre al símil de la nau que fa el seu curs orientada per un punt de referència, fins que se suscita un debat entre els tripulants sobre la idoneïtat o no del rumb pres; mentre es resol la discussió, el vaixell segueix la ruta que feia des d'abans d'iniciar-se el debat, tot i que això implique anar en una direcció inoportuna.

Per la seua part, les cinc ocurrències de lèxic mariner que es comptabilitzen als versos 3-6 del poema Lxxvi conformen una imatge en què el jo poètic, decebut per una experiència amorosa frustrada, s'identifica amb un mariner que, amb l'escandall, va cercant el punt adequat per a fondejar i, així, preservar-se dels vents; una operació inútil perquè el port que abans el preservava de les inclemències - la dama en la qual havia posat tota la seua confiança- $s$ 'ha transformat en una platja oberta i desprotegida que no ofereix les garanties més mínimes.

Al brevíssim poema LXXXII — vuit versos-, es tracta el tema dels designis de la providència divina, sempre subjectes a una manca de causalitat tal que els fa inescrutables. Això s'exemplifica en els dos primers versos, que contenen els quatre mots mariners constitutius d'una imatge nàutica: quan Déu determina que una embarcació s'enfonse, no hi ha res que ho puga impedir; se'n fan malbé tant les àncores com l'ormeig, malgrat que estiga fondejada en un port segur. També són quatre les mostres de lèxic mariner que trobem al poema $\mathrm{C}-232$ versos-, on s'allludeix a la lluita entre intellecte i instint irracional, així com a la dificultat de vèncer l'impuls de les passions. Aquesta situació porta el jo líric 
a comparar-se amb el navegant incapaç de contrarestar la força dels vents i de controlar el rumb de la seua nau (v. 5-6).

En últim lloc, ens referirem als poemes on només es documenten tres ocurrències de lèxic mariner (IV, VII, XxVI, XCII, XCVIII i CXXVII), mentre que deixarem fora del nostre recorregut els que només en presenten dues o una, per la seua escassa productivitat, ja que, en aquests casos, es tracta d'usos rectes que no constitueixen imatges poètiques. Al poema Iv, el jo líric planteja les fortes tensions que li provoca haver de resoldre entre amar honestament la dama o fer-ho d'una manera deshonesta, fins que, finalment, es decideix per la primera alternativa. Aquesta situació s'explica amb un símil (v. 9-I2): el de l'estat revolt de la mar quan bufen dos vents contraris (llevant i ponent), que només es resol quan el més poderós de tots dos aconsegueix imposar-se. Per la seua part, al poema viI, el lèxic relacionable amb el camp que estudiem conforma una expressiva hipèrbole (v. 67-68) mitjançant la qual el jo poètic manifesta el seu desig d'estimar l'amada «fins que del riu Segre / l'aygua corrent amunt se puga stendre», és a dir, fins a l'eternitat, ja que, lògicament, no és previsible que les aigües d'un riu canvien en sentit oposat la direcció natural del seu curs. Al xxvi (v. 57-58), el jo poètic manifesta que és tan profund l'amor que sent per l'amada que un escandall no aconseguiria tocar-ne el fons, el límit. En la composició XCII, l'oposició port segur / platja deserta (v. 57) s'usa per a explicar la desorientació que provoca l'amor compost — corporal i espiritual alhora- enfront del qual s'esdevé quan cadascuna d'aquestes opcions contràries opera independentment. El poema XCVIII s'obri amb el reconeixement del jo líric d'haver seguit un mal camí, de manera que "guiat per les falses ensenyes / só avengut a perillosa riba» (v. 3-4), així com aquell que busca les terres del sud guiant-se pel vent que bufa del nord (v. 7-8). Finalment, en l'extens poema cxxviI -430 versos-, la veu poètica, des de la vellesa, fa balanç de la seua vida i afirma, amb tristesa, que ja no espera cap novetat positiva: «no·m poden més tornar los vents / en algun port» (v. 56-57).

Comptat i debatut, el lèxic mariner serveix a Ausiàs March per a construir una sèrie de símils, metàfores o allegories que, en termes generals i fonamentalment, incideixen en els motius recurrents següents:

I. El procés amorós concebut com a navegació entrebancada de riscs, com els que han d'afrontar els mariners davant dels vents contraris o dels canvis sobtats de l'oratge.

2. La identificació de qui es creia bon amador i que, tanmateix, cau en l'amor que teòricament rebutjava amb el pilot que, malgrat la seua llarga experiència, davant d'unes determinades circumstàncies, perd el control i erra el rumb.

3. Les inèrcies que ens porten a ajornar solucions definitives a l'hora d'elegir entre l'amor honest i el que no ho és, com els mariners d'una nau que, mentre perden el temps discutint el rumb correcte que han de seguir, persisteixen en la seua navegació erràtica.

4. El triomf de l'amor honest després del debat intern entre opcions oposa- 
des, com quan la mar, agitada per vents contraris, es calma per l'acció del més potent.

5. L'equiparació de la profunditat de l'amor del jo líric amb un punt de la mar en què l'escandall no pot arribar a tocar el fons. Aquest amor durarà fins que es produïsca el fet impossible que el curs d'un riu varie la seua direcció natural en sentit absolutament oposat, $o$, fins i tot, més enllà de l'eventual mort de l'amant.

6. La dificultat humana per a discernir entre el bé veritable (virtut) il'aparent (inclinacions instintives) $\mathrm{i}$ la necessitat de guiar-se per la virtut, a diferència del pilot que navega de nit, sense brúixola ni carta de navegació, per rutes perilloses, o de la nau que, sense la direcció del nauxer i mal orientada per falses senyes, acaba estavellant-se de ple contra les roques.

7. La identificació de la vida terrenal i dels béns materials com una mar profunda i perillosa en què tots acaben ofegant-se.

8. La inescrutabilitat dels designis de Déu, la qual pot explicar que un vaixell fondejat en un port segur, sense causa raonable, es veja desproveït sobtadament de les àncores i de l'ormeig i acabe enfonsant-se.

En qualsevol cas, com afirma Leveroni: «Totes les vegades que el mar es fa present en els ... versos [marquians] no és sinó per a deixar-hi el seu perfum intacte ... per a fer més patent el miracle de l'aventura poètica. La seva presència dóna una volada i una suggestió rares a les poesies on apareix» (I 52 ). Les imatges marineres són les paràboles que illustren la filosofia complexa de March, la condensació d'un discurs moral i, sobretot, una mena de retaule literari en què es visualitza l'univers estètic i conceptual de l'autor.

\section{RAFAEL ALEMANY I FRANCESC XAVIER LLORCA IBI UNIVERSITAT D'AlACANT}

\section{REFERÈNCIES}

Aguiló, Cosme. «"Bullirà el mar com la cassola en forn”: el món mariner en la poesia d'Ausiàs March». Estudis de Llengua i Literatura Catalanes 52 (Miscellània Joan Veny 8). Barcelona: Publicacions de l'Abadia de Montserrat, 2006. 5-20.

Alcover, Antoni M. i Francesc de B. Moll. Diccionari català-valencià-balear. Palma: Moll, i930-1962. Io v.

Alemany, Rafael, dir. Diccionari del lèxic de les poesies d'Ausiàs March. València: Denes, 2008.

Anton, Josep. Refranys de vora mar. Barcelona: Noray, I995.

Coromines, Joan. Diccionari etimològic $i$ complementari de la llengua catalana. Barcelona: Curial, I980-1991. 9 v. 
Deyermond, Alan. «De "gran nau” a "aspra costa”: imaginería, semántica y argumentos en el poema 2 de Ausiàs March». Poesía de cancionero del siglo xv. Estudios seleccionados. Ed. a cura de Rafael Beltrán, José Luís Canet i Marta Haro. València: Universitat de València, 2007. 79-93. [Versió original anglesa: «From «gran nau» to «aspra costa»: Imagery, Semantics and Argument in Ausias March's poem 2.» Homenaje a Hans Flasche: Festchrift zum 80 Geburstag. Ed. a cura de Karl-Hermann Körner i Günter Zimmermann. Stuttgart: Franz Steiner Verlag, I 99 I. 48 5-498]

Dolç, Miquel. «Ausiàs March, poeta mediterrani». Revista Valenciana de Filología VI. I (1959): 35-54. [Reed.: Estudis de crítica literària. De Ramon Llull a Bartomen Rosselló-Pòrcel. Barcelona: Publicacions de l'Abadia de Montserrat, I994. 56-80]

Espinosa, Antonio, Fernando Sáez i Rocío Castillo. Puertos y navegación en las costas valencianas meridionales ( $s$. I-X $d C$ ). Oxford: BAR International Series I 475, 2006.

Esteve, Joan. Liber Elegantiarum. Facsímil de l'original de I489. Castelló de la Plana: 1988.

Flam, Bernard Paul. A Concordance of the Works of Ausiàs March. Ann Arbor (Michigan): University Microfilms Inc., I990. 3 v. [Reproducció de la tesi doctoral presentada a la University of Wisconsin el i 962]

GARCIA, Marinela, ed. Lo passi en cobles (1493). Alacant: Institut Interuniversitari de Filologia Valenciana; Barcelona: Publicacions de l'Abadia de Montserrat, 2002.

Guiral-HadziIossif, Jaqueline. Valencia, puerto mediterráneo en el siglo XV (I 4 IO-I 25). València: Edicions Alfons el Magnànim, I 989.

Hauf, Albert G. «El lèxic d'Ausiàs March: primer assaig de valoració i llista provisional de mots i freqüències». Estudis de Llengua i Literatura Catalanes 6 (Miscellania Pere Bobigas 3). Barcelona: Publicacions de l'Abadia de Montserrat, I983. I 2 I-224.

Jal, Auguste. Glossaire Nautique. París, I 848.

Jaume I. Llibre dels fets del rei en Jaume. Ed. a cura de Jordi Bruguera. Barcelona: Barcino, I 99I. 2 v.

Lara Pozuelo, Antonio. Concordances i index de mots de les poesies d'Ausiàs March. Barcelona: Barcino, 2000. [CD-ROM]

Leveroni, Rosa. «Les imatges marineres en la poesia d'Ausiàs March». Bulletin of Hispanic Studies 28 (I95 I): I 5 2-I66.

LlorCA, Francesc-Xavier. El llenguatge mariner de la comarca de la Marina. Alacant: Universitat d'Alacant, I998. [Tesi doctoral]

March, Ausiàs. Poesies. Ed. a cura de Pere Bohigas 1952-I959, revisada per Amadeu J. Soberanas i Noemí Espinàs. Barcelona: Barcino, 2000.

Mayolas, Mireia. La galera reial. Barcelona: Museu Marítim, I 996.

Medina, Pedro de. Regimiento de navegación. Facsímil de l'original de 1536. València: Librerías París-Valencia, I993.

Miralles, Carles. «Sobre les comparacions marines en la poesia d'Ausiàs 
March.» Ausiàs March: textos $i$ contextos. Ed. a cura de Rafael Alemany. Alacant: Institut Interuniversitari de Filologia Valenciana i Departament de Filologia Catalana de la Universitat d'Alacant; Barcelona: Publicacions de l'Abadia de Montserrat, I997. 28 I-296.

Nieto, Lidio. Tesoro lexicográfico del español marinero anterior a $1726 . \mathrm{Ma}-$ drid: Arco Libros, 2002.

Roig, Jaume. Espill. Ed. a cura d'Antònia Carré. Barcelona: Quaderns Crema, 2006.

Santanach, Joan i Joan Torruella, ed. Ausiàs March, Poesies. Banc de bases textuals en DBT. Barcelona: Barcino, 2005. [Publicació en CD-ROM que reprodueix digitalment, acompanyada de les concordances corresponents, la reedició de Pere Bohigas publicada l'any 2000]

Torró, Jaume. «El patró que sorgia en platja i l'enarratio auctorum». Estudi General. Revista de la Facultat de Lletres de la Universitat de Girona 22.2 (1999): 353-364.

Vidos, Benedek Elemér. Storia delle parole marinaresche italiane passate in francese. Florència: Leo S. Olschki Editore, 1939.

WinTER, Heinrich. La nau catalana de I450. Barcelona: Diputació de Barcelona, 1986.

ZimmermanN, Marie-Claire. «Ausiàs March: la Mediterrània com a metàfora». La Mediterrània: realitat i metàfora. València: Universitat de València, I993. 5 I-64.

—. «Les métaphores de la mer dans la poésie d'Ausiàs March». Ibérica 2 (1979): 333-347. 